\title{
Endoprotector: Protective box for safe endoscopy use during COVID-19 outbreak
}

\section{두)(웅}

\author{
Authors \\ Sara Campos, Cátia Carreira, Pedro Pinto Marques, Ana Vieira
}

Institution

Gastroenterology Department, Hospital Garcia de Orta, Portugal

submitted 12.5 .2020

accepted after revision 18.5 .2020

Bibliography

DOI https://doi.org/10.1055/a-1180-8527 |

Endoscopy International Open 2020; 08: E817-E821

(c) Georg Thieme Verlag KG Stuttgart · New York elSSN 2196-9736

Corresponding author

Sara Campos, Hospital Garcia da Orta - Gastroenterology,

Av. Torrado da Silva, Almada 2805-267, Portugal

Fax: + 351212957004

saratcampos@gmail.com

\section{ABSTRACT}

Background and study aim Outbreak of COVID-19 began in Wuhan in December 2019 and has rapidly spread from
China to the rest of the world. Although it is primarily transmitted by contact and droplets, aerosol-generating procedures also seem to carry the possibility of airborne viral transmission. As such, upper gastrointestinal endoscopy can be considered a risky procedure, with several position statements recommending the adoption of safe practices in endoscopic procedures. This article aims to describe an additional tool to protect healthcare personnel during endoscopy.

Methods A covering box made of acrylic plastic, named Endoprotector, was designed to cover the patient's head, while taking into consideration movements performed by patients and healthcare staff during an endoscopic procedure.

Results A cough simulation using fluorescent dye confirmed the potential benefit of the box during endoscopy, thus protecting healthcare staff from air droplets. The feasibility and practicality of the box was also tested with patients during endoscopy.

Conclusion The reusable Endoprotector is easily and affordably manufactured and may reduce air droplets and airborne transmission of SARS-CoV-2 and other microorganisms during endoscopy.

\section{Introduction}

In December 2019, the first cases of pneumonia of unknown etiology were detected in Wuhan, China, and a new coronavirus, called SARS-CoV-2, was extracted from lower respiratory tract samples of several patients [1].

Since then, it has rapidly spread worldwide, with the World Health Organization having declared the coronavirus disease (COVID-19) outbreak as a pandemic [2]. To date, more than 3 million COVID-19 cases, through more than 200 countries, and more than 200,000 related deaths have been confirmed [3].

SARS-Cov-2 human-to-human transmission occurs primarily through contact or air droplets [4]. Contact can be direct, from infected people, or indirect, through surfaces in the immediate environment or objects used by the infected person. Transmission by respiratory droplets (droplets with $>5-10 \mu \mathrm{m}$ ) occurs when a person is in close contact with an infected person, with the highest risk being within approximately 1 meter. Airborne transmission refers to presence of microbes within droplet nuclei, particles $<5 \mu \mathrm{m}$ in diameter, which can remain in the air for longer periods of time and be transmitted to others over distances greater than 1 meter. In the context of COVID-19, although not currently confirmed to be an airborne virus, airborne transmission may be possible in specific circumstances and settings in which procedures or support treatments that generate aerosols are performed.

Despite healthcare personnel working in endoscopy units not being directly involved in the diagnostic and therapeutic evaluation of COVID-19-positive patients, upper gastrointestinal endoscopy should still be regarded as a risky procedure. Apart from the risk associated with close contact and respiratory droplets, endoscopy may also be considered an aerosol generating procedure (AGP), for which risk of exposure and subsequent infection of endoscopy personnel may be increased. In fact, a recent study [5] confirmed the significant 


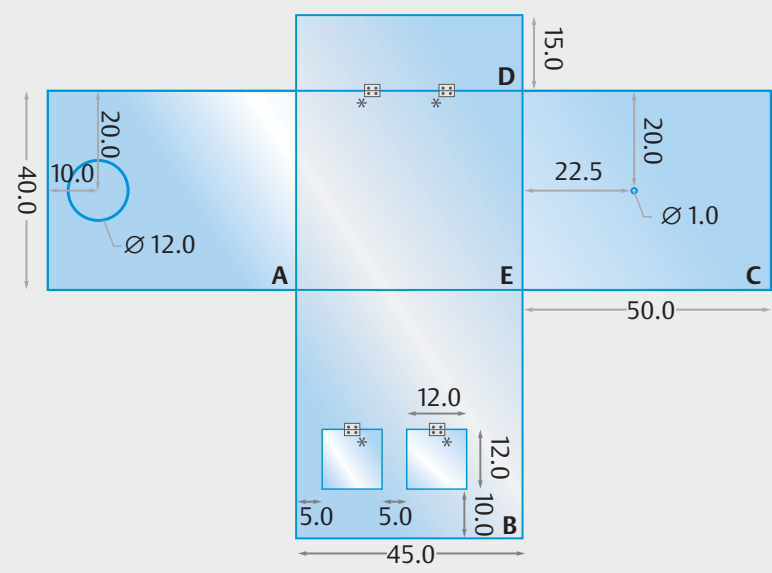

- Fig. 1 Endoprotector schematic, with Faces A, B, C, D and E. Al dimensions are in centimeters. ${ }^{*}$, hinges.

and unrecognized exposure of the endoscopist's face to potentially infectious biologic samples during endoscopy.

In this sense, establishing infection prevention measures within an endoscopy department is essential for creating a high-quality and safe environment to protect both patients and personnel. Recommendations regarding pre-screening of patients and protective measures in an endoscopy department have been published recently [6-8].

In an attempt to increase safety of the staff during the procedure, a transparent box placed over the patient's head may help limit droplets and aerosol dissemination.

\section{Materials and methods}

\section{Design}

A cardboard box prototype was first made to adjust the measurements of the box and exclude any potential limitation of movement during endoscopy. Different members of the endoscopy medical and nurse team evaluated the model and different patient morphotypes were tested to confirm that the prototype fitted all types of healthcare personnel and patients.

A schematic with the model dimensions can be seen in $>$ Fig. 1 . The box measures 40 (width) $\times 45$ (length) $\times 50$ (height) $\mathrm{cm}$. The following features of each wall were taken into consideration:

In $\triangleright$ Fig. 1 Face A, wall for scope introduction - at $4 \mathrm{~cm}$ above the mattress, one round opening of $12 \times 12 \mathrm{~cm}$ was created for accessing the patient's mouth and performing endoscopy. A small ledge $(1.5 \mathrm{~cm})$ should be added to the opening to facilitate the insertion of a single-use barrier arm sleeve (for extra reduction of droplets scatter from the patient's mouth).

In $>$ Fig. 1 Face B, wall for access to patient's head by nurse and anesthesiologist - at $10 \mathrm{~cm}$ above the mattress, two square openings of $12 \times 12 \mathrm{~cm}$ were created to allow maneuvering of the patient's head. When these openings are not needed, they can be closed.

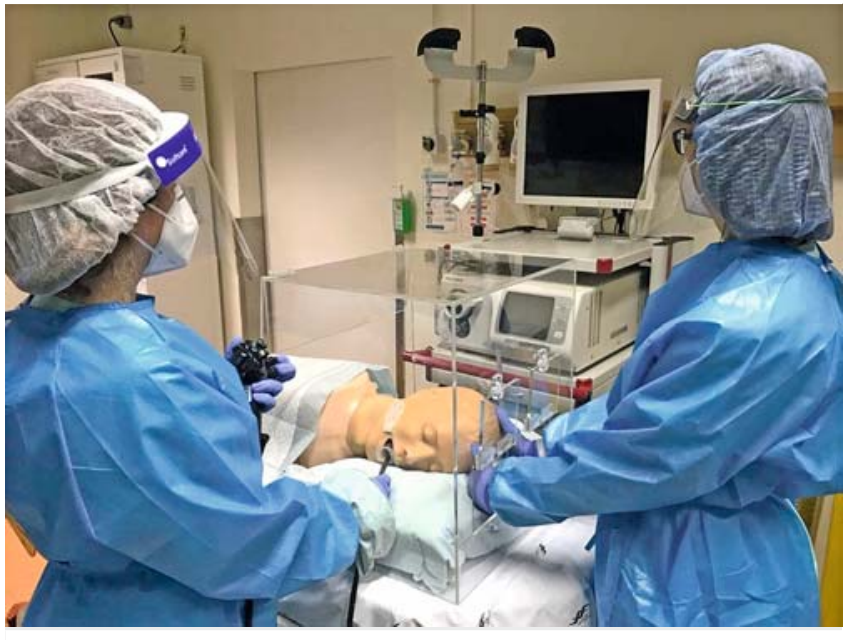

Fig. 2 General view of the Endoprotector acrylic endoscopic box.

In $>$ Fig. 1 Face C, wall for air aspiration - a small round opening of $1 \mathrm{~cm}$ was created, to serve as a connection to an air aspiration tube and promote a negative pressure environment inside the box.

In $>$ Fig. 1 Face D, wall for the patient's neck and shoulders a front tilting panel with $15-\mathrm{cm}$ height can be used, depending on the size of the patient's neck and shoulders, for extra protection.

In $>$ Fig. 1 Face E, ceiling wall, there are no special features.

The final Endoprotector endoscopic box was made of acrylic plastic (6-mm thickness) with all above-mentioned characteristics, as presented in $>$ Fig. $\mathbf{2}$ and $\boldsymbol{\nabla}$ Fig. $\mathbf{3}$.

Following each procedure, the device should be decontaminated according to the general disinfection policies in the COVID-19 context. Because the box is made of acrylic plastic, cleaning the inner and outer parts with soap and water is advised, as regular disinfectants such as bleach can damage it. Afterwards, the box should be disinfected with a $70 \%$ alcohol solution.

\section{Testing}

To confirm the protective effect of the box, a simple test was devised based on a recent paper regarding barrier enclosure during endotracheal intubation [9]. An endoscopist was positioned at the face and a nurse at the head of an airway mannequin. Both used standard personal protective equipment (PPE). A forceful cough was then simulated to generate a spread of air droplets and aerosols, using a small latex balloon containing 10 $\mathrm{mL}$ of fluorescent dye diluted in $10 \mathrm{~mL}$ of water placed in the mannequin's pharynx. The balloon was inflated with compressed oxygen that was run through tubing inside the mannequin until the balloon burst. The explosion of the balloon was assumed to represent a rough reproduction of a cough. The experiment was made without ( $\mathbf{F i g . 4}$ ) and with ( $\vee$ Fig.5,

- Fig.6) the aerosol box. After each simulation the scene was illuminated with ultraviolet light to visualize the spreading of the dye. 


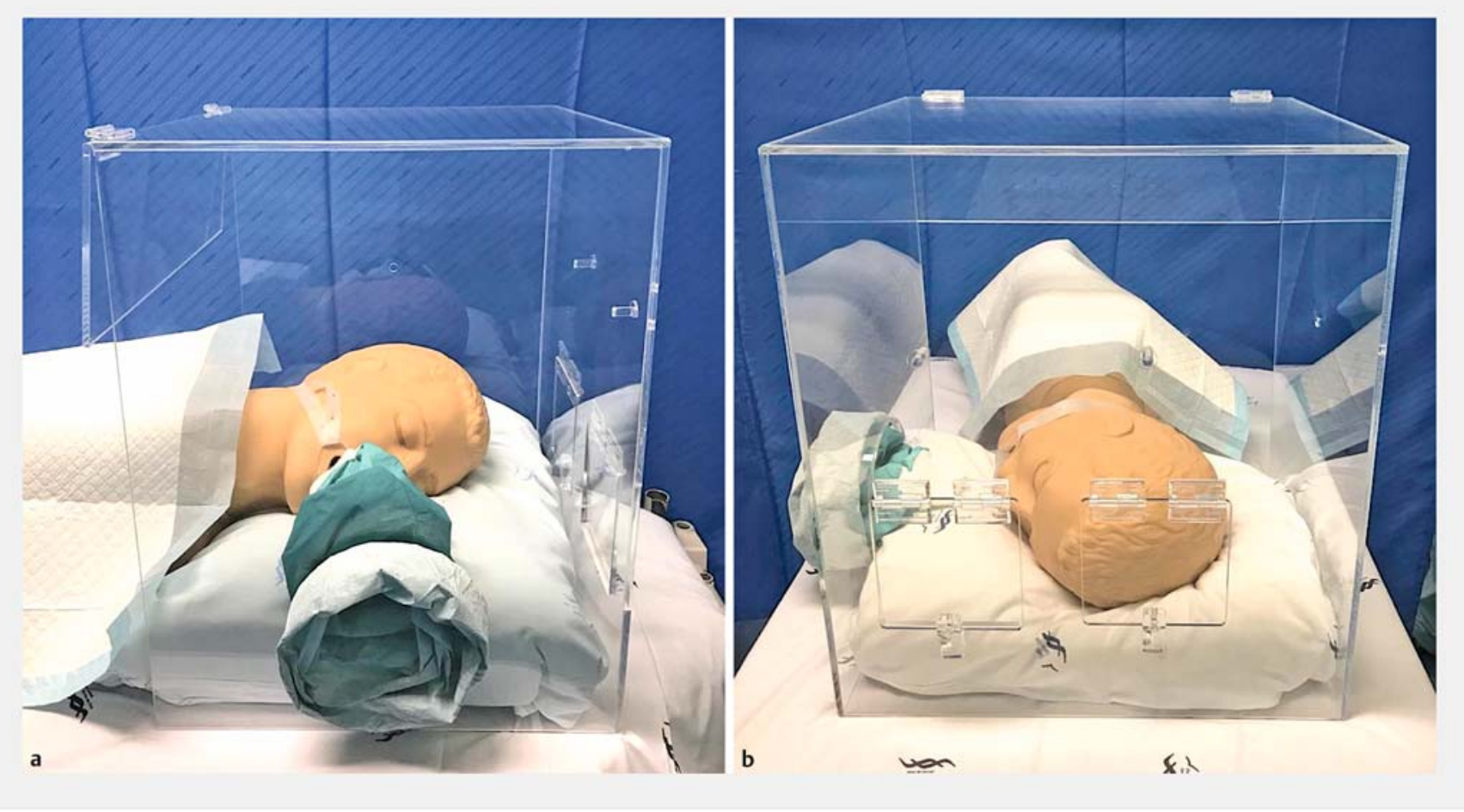

Fig. 3 The Endoprotector acrylic endoscopic box. a Face A. b Face B.
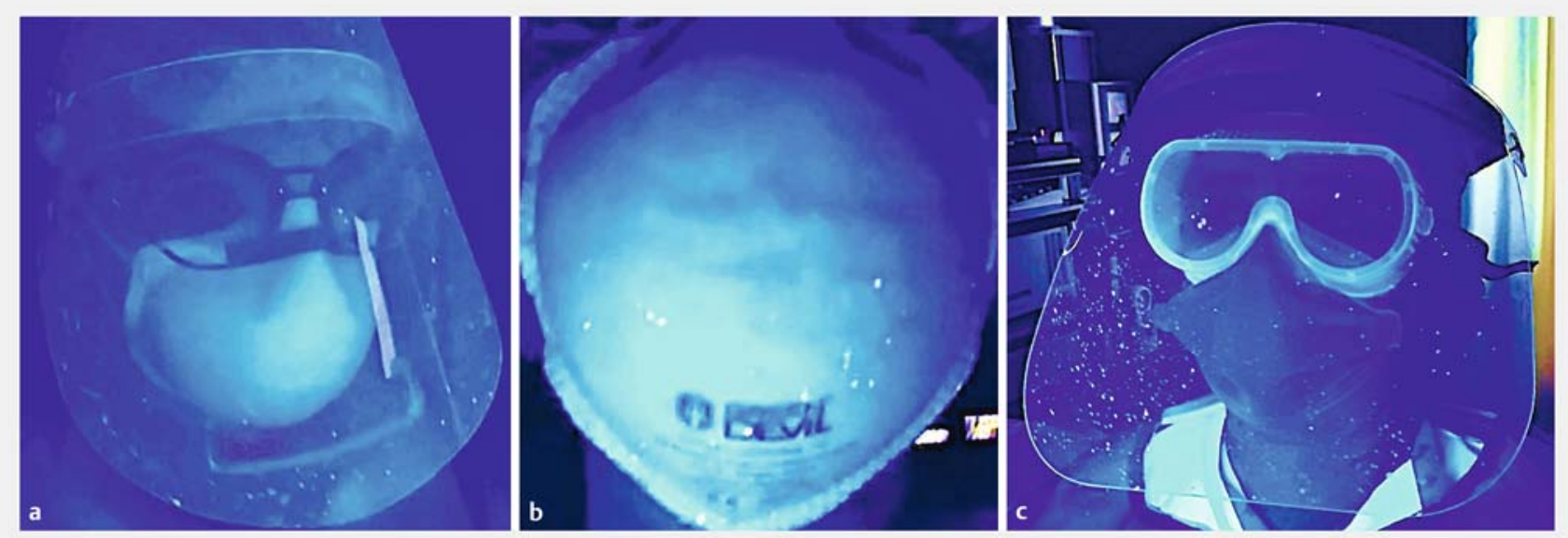

- Fig.4 Air droplet dispersion in a simulated cough during endoscopy without the Endoprotector. a Endoscopist's face. b Endoscopist's mask, behind the face shield. c Nurse's face.

\section{Results}

With exclusive use of PPE ( $\mathbf{F i g . 4}$ ), dye was found on both the endoscopist's and the nurse's face shields, facemasks, neck, gowns, and gloves. Contamination occurred on the bed sheet, floor, cupboard surface, wall, and a computer located up to 2 meters from the head of the patient.

With the aerosol box ( $\mathbf{F i g . 5 , ~}>$ Fig.6), only the inner surface of the box, the endoscopist's glove and nurse's gloves, gowned forearms and gown were contaminated. Dye was also found on the bed sheet caudal to the box. No other surfaces seemed to be contaminated.

The Endoprotector was later tested in patients. Performing endoscopy was possible without any major constraints. A minor inconvenience was noted regarding the repetitive introduction of the endoscopist's hand through the arm sleeve when inserting instruments through the working channel, making the procedure somewhat more cumbersome. 

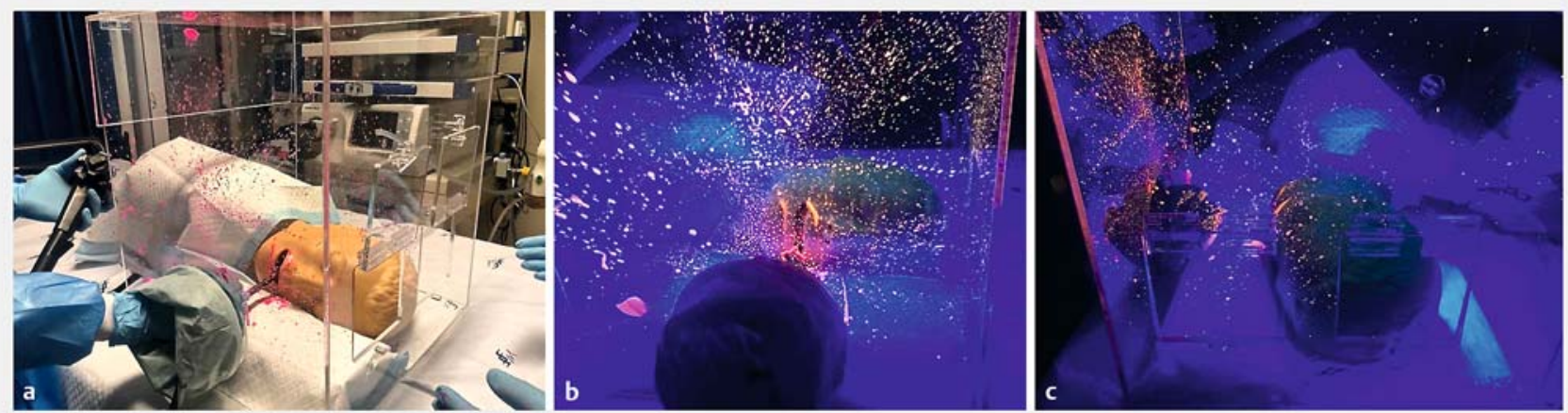

- Fig.5 Air droplet dispersion in a simulated cough during endoscopy with the Endoprotector. a General view under white light. b Face A under UV light. c Face B under UV light.

\section{Discussion}

It is widely accepted that SARS-CoV-2 is mainly spread via air droplets and direct and indirect contact, but there is increasing evidence that airborne spread is possible during AGP. In addition, there are statistical models that suggest substantial spread by undocumented infections [10], explained by reports of asymptomatic carriers unknowingly spreading the infection to close contacts [11] and findings that suggest detectable viral loads similar in symptomatic and asymptomatic patients [12]. Carriers with false-negative tests are also a concern.

In the current COVID-19 pandemic, endoscopists, anesthesiologists, and nurses may be exposed to coronavirus during endoscopy due to inhalation of droplets, direct and indirect contact $[13,14]$. During endoscopy, the patient may also aspirate, cough, retch, and require oral suction, which also carry a substantial risk of aerosolization. Viable virus has been detected in aerosols up to 3 hours after AGP [15]. As such, upper gastrointestinal endoscopy may potentially be included among the high-risk AGP, with several societies, namely the European Society of Gastrointestinal Endoscopy and the European Society of Gastroenterology and Endoscopy Nurses and Associates, advising that such procedures should be performed with the highest level of protection against COVID-19, for both patient and health care personnel [8]. To reduce the risk of virus transmission, multiple infection prevention and control measures must be implemented to enhance patient safety and protect healthcare personnel.

We describe an easily and affordably manufactured barrier that may help protect clinicians during upper endoscopy procedures. To the best of the authors' knowledge, only one other "aerosol box" has been developed, specifically for use during endotracheal intubation [9]. Acrylic plastic was chosen due to its ease of shaping, cleaning, and maintenance. A prototype cardboard box was first created to adjust the box measurements and test the feasibility (possible restriction of hand movement during the procedure) and the practicality of its use (box disinfection and storage). The protective effect of the Endoprotector was confirmed in the simulation test, for both endoscopists and nurses. The box was tested in patients with-

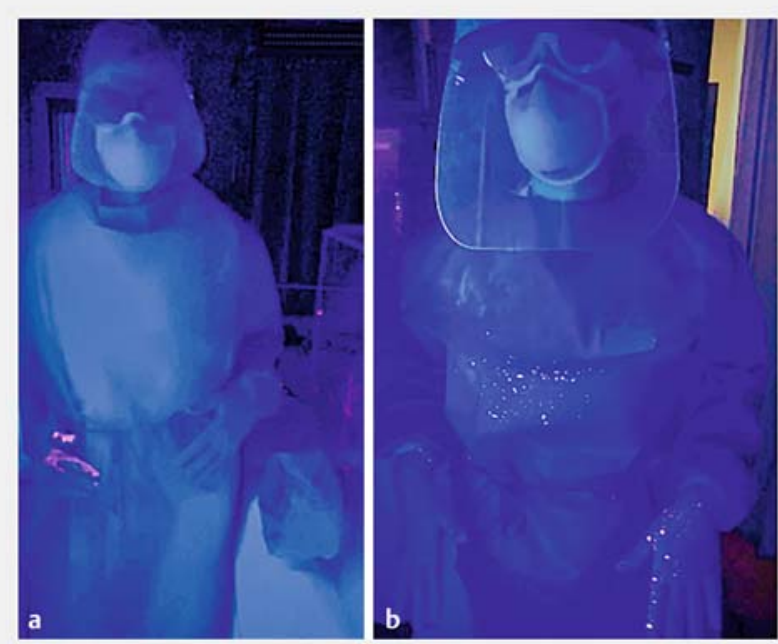

- Fig. 6 Air droplet dispersion in a simulated cough during endoscopy with the Endoprotector. a Endoscopist. b Nurse (with "open doors" in Face B).

out major limitations in performance of endoscopy, either by endoscopists or by the nurses.

Nonetheless, this model has some limitations. The simulation method, as previously described [9], is not validated for projectile direction, speed or turbulence of a true cough, nor is it matched for particle-size distribution. Two restraints regarding the Endoprotector itself have also to be mentioned. First, the air droplet dispersion to the forearms and gown of the nurse were due to the fact that both doors had been opened to access the patient's head. Many times, this action is not taken during endoscopy and the doors are closed. Second, there was dispersion of air droplets to nearly the entire bed sheet distal to the head of the patient. This was probably fostered by the fact that the mannequin was not whole-body. Still, a more hermetic closure around the patient's shoulders and dorsum, for example, using a flexible waterproof coating, could 
be used to potentially reduce air leakage and improve the negative pressure effect.

\section{Conclusion}

In conclusion, the Endoprotector represents an additional tool for potential droplet and aerosol reduction during upper gastrointestinal endoscopy. This device is not a replacement for other PPEs, but may help prevent current COVID-19 pandemic spread, and in future outbreaks of similar severe respiratory tract infections, during endoscopic procedures.

\section{Competing interests}

The authors declare that they have no conflict of interest.

\section{References}

[1] Zhu N, Zhang D, Wang W et al. A novel coronavirus from patients with pneumonia in China, 2019. N Engl J Med 2020; 382: 727-733

[2] WHO Director-General's opening remarks at the media briefing on COVID-19. 2020: Available from: https://www.who.int/dg/speeches/ detail/who-director-general-s-opening-remarks-at-the-media-briefing-on-covid-19-11-march-2020

[3] Coronavirus disease (COVID-19) Pandemic. Available from: https:// www.who.int/emergencies/diseases/novel-coronavirus-2019

[4] Modes of transmission of virus causing COVID-19. 2020: Available from: https://www.who.int/news-room/commentaries/detail/ modes-of-transmission-of-virus-causing-covid-19-implications-foripc-precaution-recommendations
[5] Johnston ER, Habib-Bein N, Dueker JM et al. Risk of bacterial exposure to the endoscopist's face during endoscopy. Gastrointest Endosc 2019; 89: 818-824

[6] Repici A, Maselli R, Colombo M et al. Coronavirus (COVID-19) outbreak: what the department of endoscopy should know. Gastrointest Endosc 2020: doi:10.1016/j.gie.2020.03.019

[7] Chiu PWY, Ng SC, Inoue $\mathrm{H}$ et al. Practice of endoscopy during COVID19 pandemic: position statements of the Asian Pacific Society for Digestive Endoscopy (APSDE-COVID statements). Gut 2020; 69: 991996

[8] ESGE and ESGENA Position Statement on gastrointestinal endoscopy and the COVID-19 pandemic. 2020: Available from: https://www. esge.com/esge-and-esgena-position-statement-on-gastrointestinalendoscopy-and-the-covid-19-pandemic/

[9] Canelli R, Connor CW, Gonzalez M et al. Barrier enclosure during endotracheal Intubation. N Engl J Med 2020; 381: 1975-1958

[10] Li R, Pei S, Chen B et al. Substantial undocumented infection facilitates the rapid dissemination of novel coronavirus (SARS-CoV2). Science 2020; 368: 489-493

[11] Bai Y, Yao L, Wei T et al. Presumed asymptomatic carrier transmission of COVID-19. JAMA 2020: doi:10.1001/jama.2020.2565

[12] Zou L, Ruan F, Huang M et al. SARS-CoV-2 Viral load in upper respiratory specimens of infected patients. N Engl J Med 2020; 382: 11771179

[13] Huang C, Wang Y, Li X et al. Clinical features of patients infected with 2019 novel coronavirus in Wuhan, China. Lancet 2020; 395: 497-506

[14] Gu J, Han B, Wang J. COVID-19: Gastrointestinal manifestations and potential fecal-oral transmission. Gastroenterology 2020; 158: 1518-1519

[15] van Doremalen N, Bushmaker T, Morris DH et al. Aerosol and surface stability of SARS-CoV-2 as compared with SARS-CoV-1. N Engl J Med 2020; 382: 1564-1567 